\title{
Hydrothermal Synthesis of Lanthanum-Doped MgAl-Layered Double Hydroxide/Graphene Oxide Hybrid and Its Application as Flame Retardant for Thermoplastic Polyurethane
}

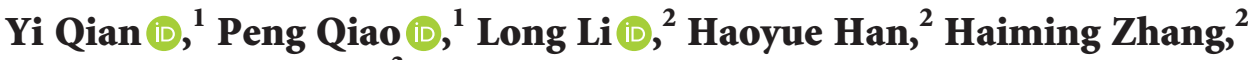 \\ and Guozhang Chang ${ }^{3}$ \\ ${ }^{1}$ College of Chemical Engineering, Qingdao University of Science and Technology, Qingdao 266042, China \\ ${ }^{2}$ College of Environment and Safety Engineering, Qingdao University of Science and Technology, Qingdao 266042, China \\ ${ }^{3}$ State Key Laboratory of High-Efficiency Utilization of Coal and Green Chemical Engineering, Ningxia University, \\ Yinchuan 750021, China
}

Correspondence should be addressed to Yi Qian; qianyi1962@126.com and Long Li; lli@yic.ac.cn

Received 6 November 2019; Revised 16 January 2020; Accepted 20 January 2020; Published 13 February 2020

Academic Editor: Bingang Xu

Copyright $\odot 2020$ Yi Qian et al. This is an open access article distributed under the Creative Commons Attribution License, which permits unrestricted use, distribution, and reproduction in any medium, provided the original work is properly cited.

A novel lanthanum-doped MgAl-layered double hydroxide/graphene oxide hybrid (La LDH/GO) with a $\mathrm{La}^{3+} / \mathrm{Al}^{3+}$ molar ratio of 0.05 was successfully synthesized by the hydrothermal method. The structure and morphology of as-prepared samples were characterized by X-ray diffraction (XRD), Fourier transform infrared spectroscopy (FTIR), and transmission electron microscopy (TEM). Then, La LDH/GO was added into thermoplastic polyurethane (TPU) to investigate its effect on flame retardancy, smoke suppression, and thermal stability of TPU composites. The cone calorimeter test (CCT) results indicated that the peak heat release rate (PHRR) and peak smoke production rate (PSPR) values of TPU with La LDH/GO decreased by $33.1 \%$ and $51 \%$ compared with neat TPU, respectively. Therefore, La LDH/GO can play a good role in flame retardancy and smoke suppression of TPU matrix during combustion. In the meantime, La LDH/GO could improve the char yield of TPU composites, which is attributed to the interaction between the physical barrier effect of GO and the catalytic effect of $0.05 \mathrm{La} \mathrm{LDH}$.

\section{Introduction}

As a type of burgeoning and widely used material, the terminal products of polymer-based materials have covered many fields such as electronic, electrical appliance, textile, furniture, transportation, and building material [1]. Thermoplastic polyurethane (TPU), an engineering thermoplastic, has been increasingly applied owing to its good flexibility, high compressive strength, and good abrasion resistance. However, like most polymers, TPU is highly flammable, which significantly increases the potential fire hazard in the place where it is used [2]. At present, in order to reduce fire damage and improve the safe level of mankind existence environment, flame retardancy has become one of the important factors that people often consider when choosing TPU for different purposes [3]. Hence, numerous flame retardants as additives have been added into TPU to enhance flame retardancy. With the enhancing awareness of environmental protection, halogen-based flame retardants are gradually being reduced or even banned due to their ecological damage during combustion [4]. Some new type of halogen-free flame retardants, for instance, organic phosphorus compounds [5], carbon nanotubes (CNTs) [6], and polyhedral oligomeric silsesquioxane (POSS) [7], have become more and more attractive in recent decades.

Layered double hydroxide (LDH), also known as hydrotalcite compounds (HT) or anionic clay, is a kind of layered compounds composed of positively charged metal hydroxide layers with interlayer spaces containing exchangeable anions. Thus, LDH has superior flame retardancy and smoke suppression properties because it has crystal-waters and hydroxyl groups $(-\mathrm{OH})$ among layered structure $[1,8]$. In recent years, there have been many studies of LDH in flame retardant polymers. Han 
et al. [9] synthesized sodium dodecyl benzene sulfonate (SDBS) intercalated $\mathrm{CoAl}, \mathrm{MgAl}, \mathrm{NiAl}$, and $\mathrm{ZnAl} \mathrm{LDH}$ as flame retardant for polystyrene (PS). The results showed that peak heat release rate (PHRR) of nanocomposites were reduced by $7 \%$ and $12 \%$ with 5 wt $\%$ MgAl-SDBS LDH and ZnAl-SDBS LDH loading, respectively. Zhang et al. [10] prepared phosphotungstic acid- (PWA-) intercalated $\mathrm{MgAl} \mathrm{LDH}$ and investigated the effect of it on the intumescent flame retardant (IFR) poly(lactic acid) (PLA) composites. When the MgAl-PWA LDH loading was $2 \mathrm{wt}$ $\%$, the PHRR of PLA composites significantly decreased from $306.3 \mathrm{~kW} / \mathrm{m}^{2}$ of neat PLA to $40.1 \mathrm{~kW} / \mathrm{m}^{2}$. The $\mathrm{lim}$ iting oxygen index (LOI) value reached 48 and passed the UL-94 V-0 rating.

The controllability of the composition and structure of LDH makes it possible to intercalate different cations. And, the flame retardancy of LDH within polymers can be further improved [8]. Lanthanum (La), a representative element of rare earths (REs), could be served as rare earth thermal stabilizers due to more coordination numbers of rare earth ion [11]. Wen et al. [12] introduced $\mathrm{La}^{3+}$ into the $\mathrm{ZnAl}-\mathrm{CO}_{3} \mathrm{LDH}$ with different $\mathrm{Zn} / \mathrm{Al} / \mathrm{La}$ molar ratios to prepared ZnAlLa- $\mathrm{CO}_{3} \mathrm{LDH}$ as heating stabilizer in poly(vinyl chloride) (PVC) resin. Their results showed that $\mathrm{ZnAlLa}-\mathrm{CO}_{3} \mathrm{LDH}$ could significantly enhance the thermal stability of PVC samples. For another rare earth element, cerium (Ce), Yi et al. [13] prepared $\mathrm{MgAlCe}-\mathrm{CO}_{3} \mathrm{LDH}$ and as stabilizer for PVC resin. They found that the PVC composite containing $\mathrm{MgAlCe}-\mathrm{CO}_{3} \mathrm{LDH}$ showed better thermal stability when the amount of $\mathrm{MgAlCe}-\mathrm{CO}_{3} \mathrm{LDH}$ filler is $3 \mathrm{phr}$.

The favourable dispersion of $\mathrm{LDH}$ in the polymer matrix is a critical prerequisite for obtaining the excellent flame retardancy of polymer-based materials. However, owing to the strong electrostatic interaction between the hydroxide layers, LDH is apt to agglomerate, which limits its flame retardant performance in polymers [14]. Graphene oxide (GO), with an ideal two-dimensional structure and large specific surface area, could solve the reaggregation of LDH in polymer matrix as a carrier [15]. For instance, Xu et al. [16] synthesized heptaheptamolybdate $\left(\mathrm{Mo}_{7} \mathrm{O}_{24}{ }^{6-}\right)$ intercalated $\mathrm{MgAl} \mathrm{LDH}$ loaded graphene hybrids and investigated their flame retardant properties in polyurethane elastomer (PUE). With $2 \mathrm{wt} \%$ RGO-LDH/Mo loading, the PHRR of PUE composites decreased by $58.6 \%$. Simultaneously, the TEM results showed that the RGO-LDH and RGO-LDH/Mo had no obvious agglomeration in PUE. Nevertheless, the research of REs doped LDH/GO hybrid as flame retardants was still rarely reported.

In this paper, $\mathrm{La}$-doped $\mathrm{MgAl} \mathrm{LDH}$ was obtained via hydrothermal synthesis. Afterwards, La LDH and GO were hybridized to synthesize La LDH/GO hybrid, i.e., La LDH sheets were loaded on GO layers. Concurrently, the structure and morphology of the as-prepared samples were characterized. Then the TPU composites filled with LDH and LDH/GO were prepared by the melt blending method. Meanwhile, the flame retardancy and smoke suppression of all TPU composites were comprehensively analyzed further.

\section{Experimental}

2.1. Materials. Sulfuric acid (98\%), hydrogen peroxide (30\%), nitric acid (68\%), aqueous ammonia (25\%), graphite powder, $\mathrm{Al}\left(\mathrm{NO}_{3}\right)_{3} \cdot 9 \mathrm{H}_{2} \mathrm{O}, \mathrm{Mg}\left(\mathrm{NO}_{3}\right)_{2} \cdot 6 \mathrm{H}_{2} \mathrm{O}, \mathrm{KMnO}_{4}$, and $\mathrm{NaNO}_{3}$ were all purchased from Sinopharm Chemical Reagent Co., Ltd. (China). $\mathrm{La}_{2} \mathrm{O}_{3}$ was bought from Shanghai Aladdin Bio-Chem Technology Co., Ltd. (China). $\mathrm{La}\left(\mathrm{NO}_{3}\right)_{3}$ solution was prepared through dissolving $\mathrm{La}_{2} \mathrm{O}_{3}$ in dilute nitric acid. Commercial TPU (9380A) was obtained from Bayer, German.

2.2. Synthesis of $L a L D H$. The as-prepared $\mathrm{La} L D H$ samples were synthesized by using precipitation and hydrothermal methods. $0.03 \mathrm{~mol} \mathrm{Mg}\left(\mathrm{NO}_{3}\right)_{2} \cdot 6 \mathrm{H}_{2} \mathrm{O}$ and $0.012 \mathrm{~mol}$ $\mathrm{Al}\left(\mathrm{NO}_{3}\right)_{3} \cdot 9 \mathrm{H}_{2} \mathrm{O}$ were dissolved in $60 \mathrm{ml}$ deionized water, and then $\mathrm{La}\left(\mathrm{NO}_{3}\right)_{3}$ solution was added into the above mixture and the $\mathrm{La}^{3+} / \mathrm{Al}^{3+}$ molar ratio was varied at 0.02 , 0.05 , and 0.1 for comparison. Concurrently, the total mole amount of $\mathrm{La}^{3+}$ and $\mathrm{Al}^{3+}$ was maintained at $0.012 \mathrm{~mol}$. After that, $\mathrm{pH}$ of the mixture was adjusted to 10 by adding dilute ammonia aqueous solution (5\%) dropwise. The mixture was heated at $65^{\circ} \mathrm{C}$ for $30 \mathrm{~min}$ with rapid stirring. Then, the resulting suspension was transferred to a $100 \mathrm{~mL}$ Teflonlined autoclave, and it was kept under $130^{\circ} \mathrm{C}$ for $12 \mathrm{~h}$. After autoclave was cooled to room temperature, the resulting precipitates were filtered, washed several times with deionized water, and dried at $60^{\circ} \mathrm{C}$ for $24 \mathrm{~h}$.

2.3. Synthesis of La LDH/GO Hybrid. GO was synthesized from graphite powder by using the Hummers method [17]. In addition, $\mathrm{La} \mathrm{LDH/GO}$ hybrid was prepared at the similar experimental conditions, except that GO solution was added to above mixture containing $\mathrm{Mg}^{2+}, \mathrm{La}^{3+}$, and $\mathrm{Al}^{3+}$ with a $\mathrm{La}^{3+} / \mathrm{Al}^{3+}$ molar ratio of 0.5 .

2.4. Synthesis of TPU Composites. TPU composites were prepared by the melt blending method. For example, a certain amount of TPU was put in the internal mixer under $180^{\circ} \mathrm{C}$ for $3 \mathrm{~min}$, and the rate of agitation was $30 \mathrm{rpm}$. Then, La LDH/GO was added to the mixer, and stirred constantly at the same temperature for $10 \mathrm{~min}$. Finally, the TPU composite contains La LDH/GO was hot-pressed for $10 \mathrm{~min}$ at $180^{\circ} \mathrm{C}$ and $10 \mathrm{MPa}$ to form sheet with the size of $100 \times 100 \times 3 \mathrm{~mm}^{3}$. Moreover, the TPU composites containing $\mathrm{MgAl} \mathrm{LDH}$ and La LDH were prepared under the same conditions, respectively. The formulas of all TPU composites are displayed in Table 1.

2.5. Characterization. X-ray diffraction (XRD) measurements were taken by using a Rigaku X-ray diffractometer (Japan) with $\mathrm{Cu}-\mathrm{K} \alpha$ tube and $\mathrm{Ni}$ filter $(\lambda=0.1542 \mathrm{~nm})$. Fourier transform infrared spectroscopy (FTIR) studies were recorded on a Nicolet 6700 FTIR spectrophotometer (USA) with $\mathrm{KBr}$ pellet technique. Scanning electron microscopy (SEM) measurements were performed by using a JSM-6700F instrument (Japan). Transmission electron microscope- 
TABLE 1: Formulas of TPU and TPU composites.

\begin{tabular}{lcccc}
\hline Sample & TPU $(w t \%)$ & MgAl LDH (wt\%) & 0.05 La LDH (wt\%) & La LDH/GO (wt\%) \\
\hline TPU & 100 & 0 & 0 & 0 \\
TPU1 & 98 & 2 & 0 & 0 \\
TPU2 & 98 & 0 & 2 & 0 \\
TPU3 & 98 & 0 & 0 & 2 \\
\hline
\end{tabular}

energy dispersive spectrometer (TEM-EDS) measurements were taken by a JEM-2100Plus instrument (Japan) with an acceleration voltage of $200 \mathrm{kV}$. Cone calorimeter test (CCT) was undertaken with a JCZ-2 cone calorimeter (China) according to ISO 5660 standard procedures. Specimens with the size of $100 \times 100 \times 3 \mathrm{~mm}^{3}$ were irradiated under a heat flux of $50 \mathrm{~kW} / \mathrm{m}^{2}$. Limiting oxygen index (LOI) measurements were carried out with an HC-2 oxygen index meter (China) according to ASTM D2863. The size of the specimens used for the test was $100 \times 6.5 \times 3 \mathrm{~mm}^{3}$. Thermalgravimetric analysis (TGA) was carried out on a DT-50 instrument (France). The samples were heated from room temperature to $800^{\circ} \mathrm{C}$. The heating rates were set as $20^{\circ} \mathrm{C} / \mathrm{min}$ (nitrogen atmosphere, flow rate of $20 \mathrm{~mL} / \mathrm{min}$ ).

\section{Results and Discussion}

3.1. Characterization of As-Prepared Samples. XRD can be used to determine the crystal structure of materials. The XRD spectra of $\mathrm{La} \mathrm{LDH}$ with different $\mathrm{La}^{3+} / \mathrm{Al}^{3+}$ molar ratio are shown in Figure 1. As can be seen from the figure, the diffraction peaks of $\mathrm{MgAl} \mathrm{LDH}$ at $2 \theta=9.9^{\circ}, 20.0^{\circ}, 34.6^{\circ}, 37.6^{\circ}$, $42.7^{\circ}, 60.8^{\circ}, 61.8^{\circ}$, and $64.7^{\circ}$ indicate the (003), (006), (012), (015), (018), (110), (113), and (116) planes of the hydrotalcite structure, respectively [18]. The interlayer spacing of $\mathrm{MgAl}$ $\mathrm{LDH}$ is $0.89 \mathrm{~nm}$ from the (003) plane, showing the intercalation of $\mathrm{NO}^{3-}$ into the interlayer gallery [19]. In addition, the interlayer spacing of all $\mathrm{La} \mathrm{LDH}$ remains unchanged after doping $\mathrm{La}^{3+}$ to MgAl LDH. With the increase of $\mathrm{La}^{3+}$ content on $\mathrm{MgAl} \mathrm{LDH}$ laminates, the intensities of three peaks between $30^{\circ}$ and $50^{\circ}$ are weakened. It is mainly because the ionic radius of $\mathrm{La}^{3+}$ is too large, which destroys the hexagonal structure of $\mathrm{MgAl} \mathrm{LDH}$. It is noteworthy that when the molar ratio of $\mathrm{La}^{3+} / \mathrm{Al}^{3+}$ is 0.1 , the impurity phase appears. Simultaneously, the peaks for (100), (110), (101), (201), and (211) planes of $\mathrm{La}(\mathrm{OH})_{3}$ can be obtained at $2 \theta=15.7^{\circ}$, $27.4^{\circ}, 28.0^{\circ}, 39.5^{\circ}$, and $48.8^{\circ}$ (JCPDS card no.83-2034) [12].

Based on the above research on $\mathrm{La} \mathrm{LDH}$ with diverse $\mathrm{La}^{3+}$ / $\mathrm{Al}^{3+}$ molar ratio, $0.05 \mathrm{La} \mathrm{LDH}$ without new phase and GO were selected to synthesis La LDH/GO hybrid. Figure 2 displays the XRD spectra of GO, $0.05 \mathrm{La} \mathrm{LDH}$ and $\mathrm{La} \mathrm{LDH} / \mathrm{GO}$. The spectrum of GO has a strong diffraction peak at $2 \theta=11.48^{\circ}$, corresponding to the (002) plane and the interlayer spacing is $0.77 \mathrm{~nm}$ according to Bragg's equation [20]. Furthermore, La $\mathrm{LDH} / \mathrm{GO}$ and $0.05 \mathrm{La} \mathrm{LDH}$ have the same diffraction peaks, but the peak intensities of La LDH/GO become weaker. Furthermore, the diffraction peak of GO disappears, indicating that $0.05 \mathrm{La} \mathrm{LDH}$ is well dispersed on GO layer.

FTIR is used to obtain information about chemical bonds or functional groups contained in materials. The FTIR spectra of GO, MgAl LDH, $0.05 \mathrm{La} \mathrm{LDH}$, and La LDH/GO

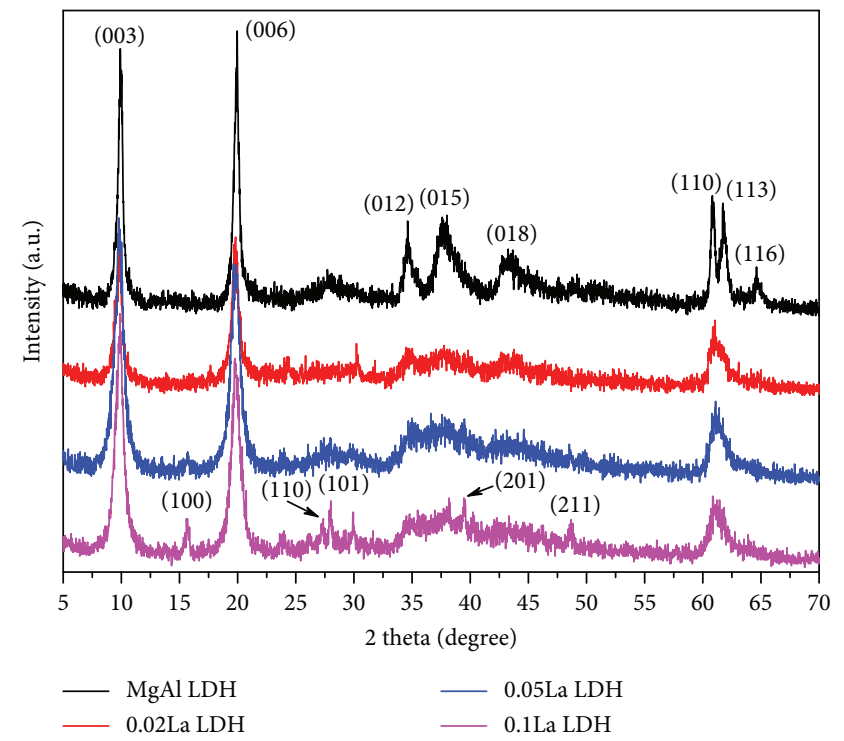

Figure 1: XRD spectra of MgAl LDH, 0.02 La LDH, 0.05 La LDH, and $0.1 \mathrm{La} \mathrm{LDH}$.

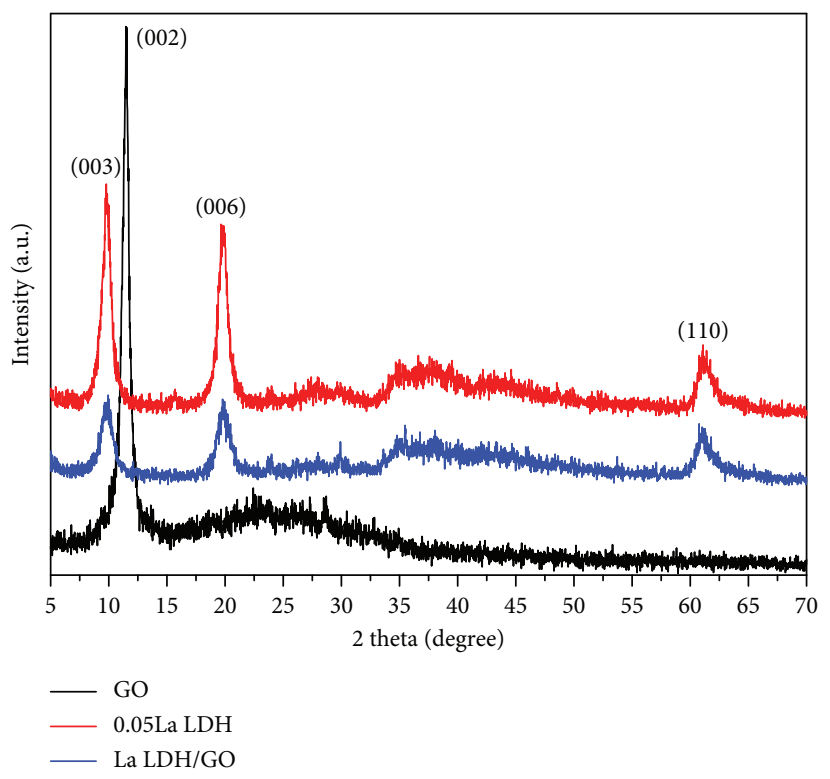

Figure 2: XRD spectra of GO, $0.05 \mathrm{La} \mathrm{LDH}$, and La LDH/GO.

are presented in Figure 3. From the figure, we could see that characteristic peaks of GO at 3395, 1721, 1402, and $1054 \mathrm{~cm}^{-1}$ are attributed to the stretching vibrations of the $\mathrm{O}-\mathrm{H}, \mathrm{C}=\mathrm{O}$, epoxy $\mathrm{C}-\mathrm{O}$, and alkoxy $\mathrm{C}-\mathrm{O}$, respectively. In addition, the absorption peak of $\mathrm{GO}$ at $1617 \mathrm{~cm}^{-1}$ is corresponded to the deformation vibration of adsorbed water 


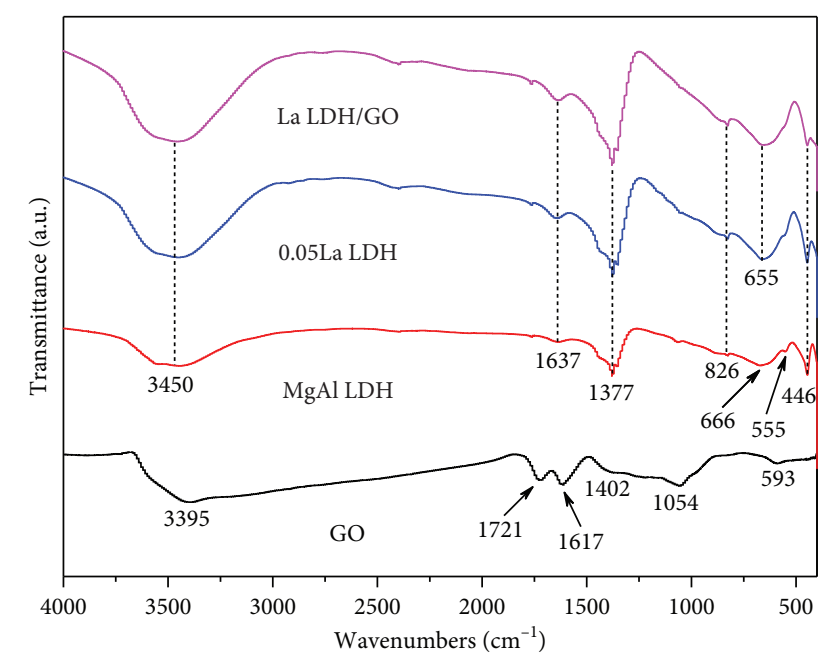

Figure 3: FTIR spectra of GO, MgAl LDH, $0.05 \mathrm{La} \mathrm{LDH}$ and La LDH/GO.

[21]. As for MgAl LDH, $0.05 \mathrm{La} \mathrm{LDH}$, and La LDH/GO, all spectra have similar trends. For instance, characteristic bands at 3450 and $1637 \mathrm{~cm}^{-1}$ are ascribed to the vibrations of $\mathrm{O}-\mathrm{H}$ and water molecules, respectively. The absorption peaks at 1377 and $826 \mathrm{~cm}^{-1}$ are assigned to the vibration of $\mathrm{NO}_{3}{ }^{-}\left(\nu_{3}\right.$ and $\left.\nu_{2}\right)$ as interlayer anion $[19,22]$. Furthermore, the characteristic bands below $700 \mathrm{~cm}^{-1}$ are attributed to the lattice vibrations of $\mathrm{Al}-\mathrm{O}$ and $\mathrm{Mg}-\mathrm{O}$ in the $\mathrm{LDH}[9,23]$. More significantly, compared with $\mathrm{MgAl} \mathrm{LDH}$, the absorption peak of $\mathrm{Al}-\mathrm{O}$ bond blue-shifts 11 wavenumbers (from $666 \mathrm{~cm}^{-1}$ to $655 \mathrm{~cm}^{-1}$ ) in the FTIR spectra of $0.05 \mathrm{La}$ $\mathrm{LDH}$ and $\mathrm{La} \mathrm{LDH} / \mathrm{GO}$. And, the Al-O peaks of $0.05 \mathrm{La} \mathrm{LDH}$ and $\mathrm{La} \mathrm{LDH/GO}$ at $555 \mathrm{~cm}^{-1}$ disappear. It is mainly because the $\mathrm{La}^{3+}$ partially replaces $\mathrm{Al}^{3+}$ and destroys the lattice structure of LDH $[12,13]$.

The morphology and internal structure of GO and La LDH/GO can be observed by TEM. It can be seen from the Figure 4(a), GO has a two-dimensional layered structure with the size of several hundred nanometers. Meanwhile, in some areas, GO layers fold each other, thus showing different degrees of restacking. This is largely due to the existence of Van Der Waals forces between GO layers. As shown in Figure 4(b), the lateral size of 0.05 La LDH platelets is around $50-100 \mathrm{~nm}$ and many $0.05 \mathrm{La} \mathrm{LDH}$ sheets appear on the GO layers, thus the folded areas are significantly reduced [22]. Owing to the successful loading of LDH on GO layers, the restacking of GO sheets is effectively inhibited. Furthermore, the elements of $\mathrm{C}, \mathrm{O}, \mathrm{N}, \mathrm{Mg}, \mathrm{Al}$ and $\mathrm{La}$ can be observed from the EDS spectrum of $\mathrm{La} \mathrm{LDH} / \mathrm{GO}$ (Figure $4(\mathrm{c})$ ). The molar ratio of $\mathrm{Mg} / \mathrm{Al} / \mathrm{La}$ is $2.4 / 1 / 0.05$ agrees with the theoretical values, indicating that $\mathrm{La} \mathrm{LDH} /$ GO hybrid is successfully synthesized.

3.2. Flame Retardancy of TPU Composites. The numerous parameters related to the potential fire hazard of the materials can be obtained by cone calorimeter, which is the most ideal test instrument for investigating the combustion performance of the materials during a fire. The heat release rate (HRR) is the most important fire characteristic parameter of the materials $[24,25]$. Figure 5 gives the HRR curves of neat TPU and TPU composites. It can be seen that neat TPU has high peak heat release rate (PHRR) with a value of $1103 \mathrm{~kW} / \mathrm{m}^{2}$, which indicates that it is highly flammable and belongs to intermediate thickness non-charring samples. As for TPU1 containing $\mathrm{MgAl} \mathrm{LDH}$, compared with neat TPU, the PHRR value decreased by $23.3 \%$ to $846 \mathrm{~kW} / \mathrm{m}^{2}$. This can be explained by the fact that $\mathrm{MgAl} \mathrm{LDH}$ absorbs heat during thermal decomposition, reducing the temperature on the surface of TPU, and decreasing the thermal decomposition and combustion rate of the polymer. Meanwhile, MgAl LDH can form a protective carbon layer on the degradation products, which prevents heat and gas transfer [26]. Furthermore, the PHRR value of TPU2 decreased by $30.3 \%$ in comparison with neat TPU. The decline in PHRR is mainly due to the further improvement of flame retardancy of $\mathrm{MgAl} \mathrm{LDH}$ by the introduction of rare earth lanthanum. Among all the samples, TPU3 has the lowest PHRR value, which is $33.1 \%$ lower than that of neat TPU, indicating the physical barrier effect of the GO sheets [27]. It is worth noting that the time taken to reach the peak of all TPU composites are less than that of neat TPU, which is attributed to the decomposition of $\mathrm{LDH}$ at low temperature.

The cone calorimeter data of neat TPU and TPU composites are displayed in Table 2. From TPU1 to TPU3, total heat release (THR) values are basically unchanged, indicating that heat is kept constant before and after combustion. But average mass loss rate (AvMLR) values decreased, showing that $0.05 \mathrm{La} \mathrm{LDH}$ and GO play the role of flame retardancy by the mechanism of charring in the TPU composites. In the meantime, the average heat release rate (AvHRR) values of TPU1, TPU2, and TPU3 decreased; in turn, the respective HRR curves also became more and more flat after reaching the peak value. Combining the results of Figure 5, it is shown that all TPU composites belong to thermally thick charring (residue forming) samples [4]. In addition, the average effective heat combustion (AvEHC), THR, AvHRR, and AvMLR values of TPU1 are all slightly higher than those of neat TPU as listed in Table 2, which indicates that the flame retardant effect of low $\mathrm{MgAl}$ $\mathrm{LDH}$ content on TPU is not significant.

In order to further comprehensively analyze the effect of La LDH/GO hybrid on the flame retardancy of TPU, an oxygen index meter was used to obtain the LOI value. Figure 6 presents LOI values of neat TPU and TPU composites. As can be seen from the figure, the LOI value of neat TPU is $21.4 \%$, while the LOI values of TPU composites are $21.8 \%, 22 \%$, and $23.2 \%$, respectively. The LOI increased only by 1.8 from neat TPU to TPU3 (with 2 wt\% La LDH/GO loading), showing that La LDH/GO fails to significantly increase the LOI value of TPU composites. Therefore, the above results show that if La $\mathrm{LDH} / \mathrm{GO}$ is used as a synergistic flame retardant, it will have a better effect on TPU matrix [28].

3.3. Smoke Suppression of TPU Composites. The fire hazard of polymer materials is not only related to heat, but also to smoke. The smoke parameters obtained by cone calorimeter can also be used to evaluate the smoke suppression 


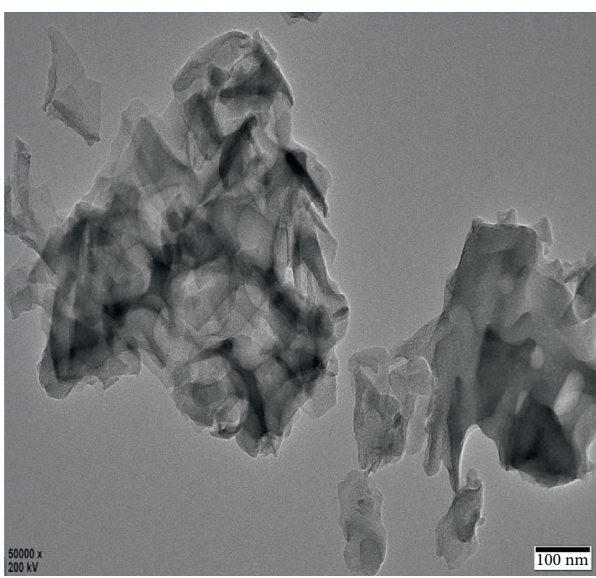

(a)

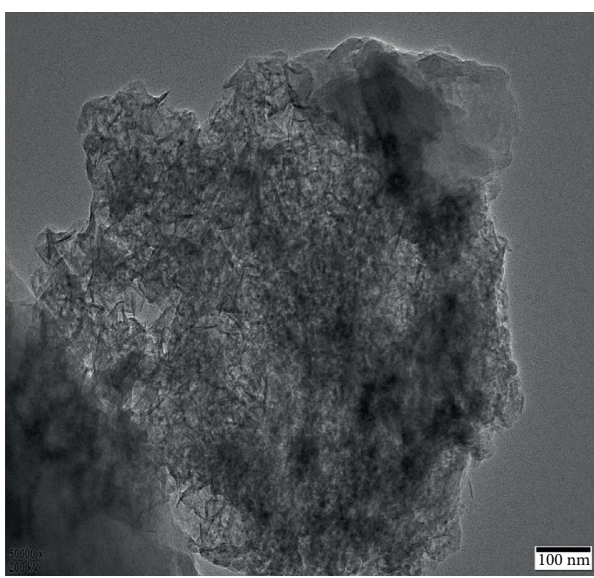

(b)

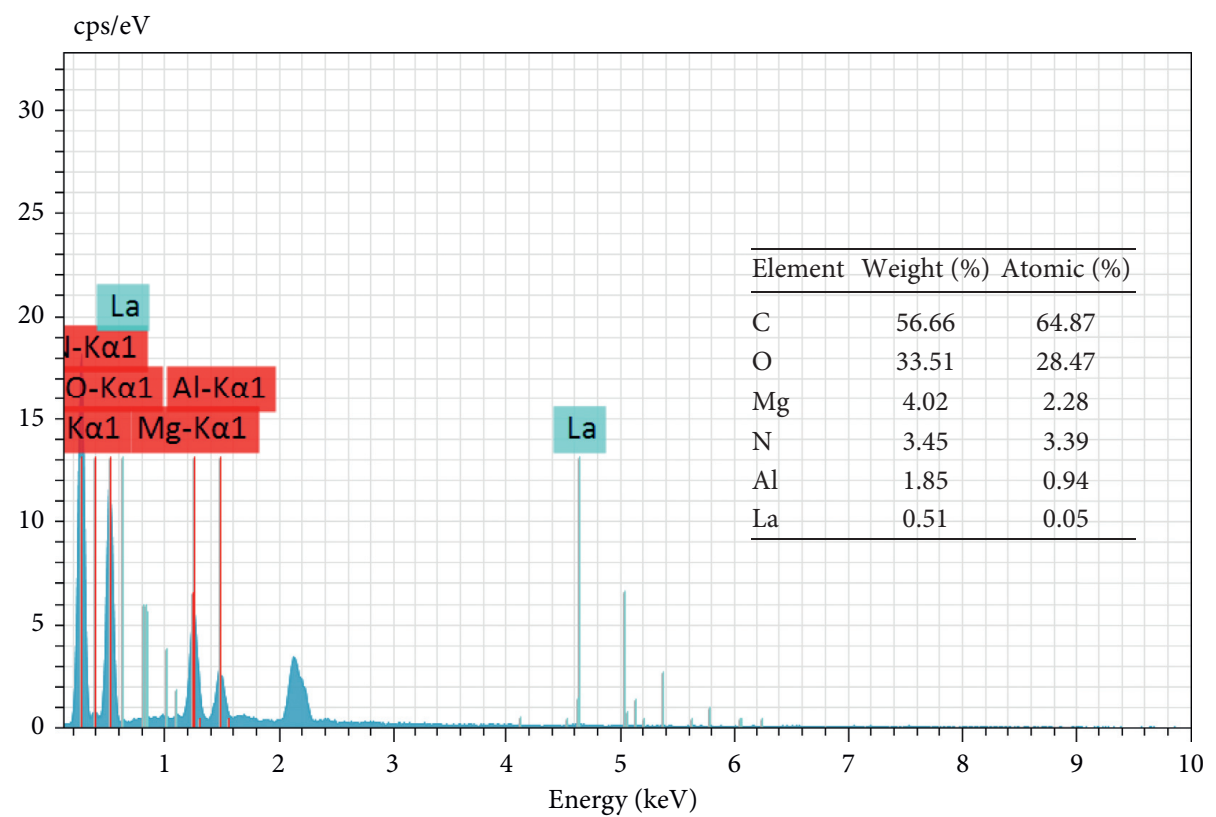

(c)

Figure 4: TEM images of (a) GO, (b) La LDH/GO, and (c) EDS analysis of La LDH/GO.

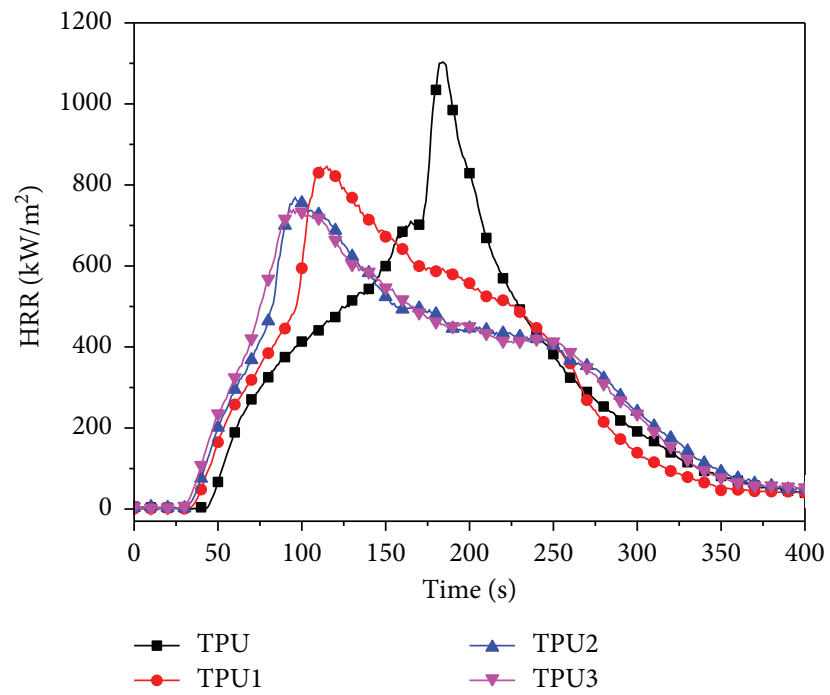

Figure 5: HRR curves of TPU and TPU composites. 
TABLE 2: Cone calorimeter data of TPU and TPU composites.

\begin{tabular}{lcccccccccc}
\hline Sample & $\begin{array}{c}\text { PHRR } \\
\left(\mathrm{kW} / \mathrm{m}^{2}\right)\end{array}$ & $\begin{array}{c}\text { THR } \\
\left(\mathrm{MJ} / \mathrm{m}^{2}\right)\end{array}$ & $\begin{array}{c}\text { AvHRR } \\
\left(\mathrm{kW} / \mathrm{m}^{2}\right)\end{array}$ & $\begin{array}{c}\text { AvEHC } \\
(\mathrm{M} / \mathrm{kg})\end{array}$ & $\begin{array}{c}\text { AvMLR } \\
(\mathrm{g} / \mathrm{s})\end{array}$ & $\begin{array}{c}\text { PSPR } \\
\left(\mathrm{m}^{2} / \mathrm{s}\right)\end{array}$ & $\begin{array}{c}\text { TSP } \\
\left(\mathrm{m}^{2}\right)\end{array}$ & $\begin{array}{c}\text { AvSEA } \\
\left(\mathrm{m}^{2} / \mathrm{kg}\right)\end{array}$ & $\begin{array}{c}\text { PCOY } \\
(\mathrm{kg} / \mathrm{kg})\end{array}$ & $\begin{array}{c}\text { PCO } \\
(\mathrm{kg} / \mathrm{kg})\end{array}$ \\
\hline TPU & 1103 & 139.1 & 261.2 & 15.6 & 0.089 & 0.100 & 13.22 & 159.6 & 0.090 & 8.802 \\
TPU1 & 846 & 139.6 & 283.8 & 16.3 & 0.092 & 0.061 & 10.62 & 142.5 & 0.063 \\
TPU2 & 769 & 140.3 & 237.2 & 15.8 & 0.078 & 0.055 & 11.06 & 129.2 & 0.043 \\
TPU3 & 738 & 140.0 & 209.8 & 13.3 & 0.068 & 0.049 & 10.76 & 106.0 & 0.006 & 0.172 \\
\hline
\end{tabular}

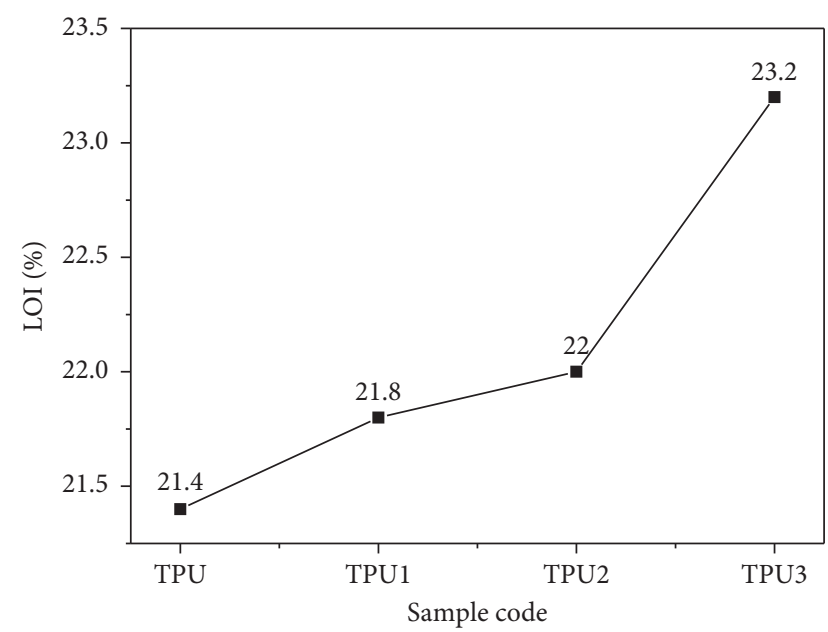

Figure 6: LOI results of TPU and TPU composites.

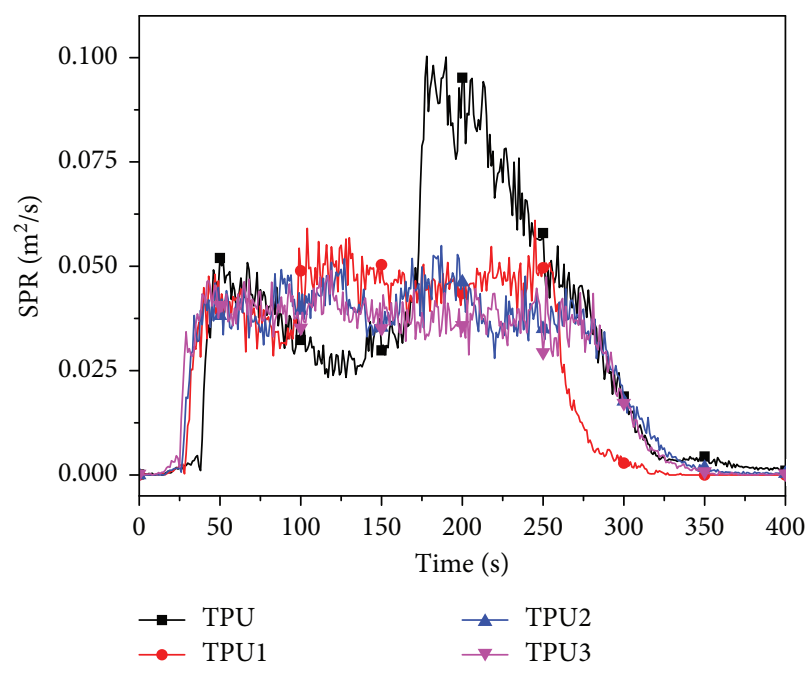

FIgURE 7: SPR curves of TPU and TPU composites.

performance of materials [29]. Figure 7 shows the smoke production rate (SPR) curves of neat TPU and TPU composites. As can be seen from Figure 7, neat TPU has the highest peak smoke production rate (PSPR) value of $0.1 \mathrm{~m}^{2} / \mathrm{s}$ in all samples, which proves that TPU produces heavy smoke during combustion process. However, compared with neat TPU, the PSPR reductions of TPU1, TPU2, and TPU3 are $39 \%, 45 \%$, and $51 \%$, respectively. The smoke suppression performance of TPU1 is attributed to the presence of $\mathrm{MgAl}$ LDH. On the one hand, the water vapor produced by thermal decomposition of LDH can dilute and absorb part of the smoke; on the other hand, the MgAl LDH lamellae also contains basic metal ions (such as $\mathrm{Mg}^{2+}$ ) besides large specific surface area, so it has a good adsorption effect on acidic gases [30]. For TPU2 containing 0.05 La LDH, the catalytic effect of rare earth lanthanum could promote the charring of TPU and form protective carbon layer, thus protecting the polymer matrix. When GO and 0.05 La LDH are incorporated into TPU, the char formation is further promoted by combining the physical barrier effect of GO [31].

Table 2 also illustrates certain smoke parameters of neat TPU and TPU composites. It can be observed that total smoke production (TSP) values of all TPU composites decreased in comparison with neat TPU. Nevertheless, the TSP values of TPU2 and TPU3 are mildly higher than those of TPU1, which is mainly attributed to the prolongation of burnout time by $0.05 \mathrm{La} \mathrm{LDH}$ and GO. Through the SPR curves of TPU composites after $250 \mathrm{~s}$, this phenomenon could also be explained. The peak $\mathrm{CO}$ yield (PCOY) and peak $\mathrm{CO}_{2}$ yield $\left(\mathrm{PCO}_{2} \mathrm{Y}\right)$ are also important parameters to characterize the smoke emission behavior of materials [31]. As shown in Table 2, from neat TPU to TPU3, the values of PCOY and $\mathrm{PCO}_{2} \mathrm{Y}$ are reduced in turn. Compared with neat TPU, the reduction for PCOY and $\mathrm{PCO}_{2} \mathrm{Y}$ of TPU3 are $93 \%$ and $98 \%$, respectively, which ascribed to the adsorption of $\mathrm{La} \mathrm{LDH}$ and $\mathrm{GO}$ on $\mathrm{CO}$ and $\mathrm{CO}_{2}$. The specific extinction area (SEA) is used to characterize the relationship between volatile products and smoke release during combustion process of materials, and it has a fine correlation with smoke parameters in large-scale experiments. As revealed in Table 2, compared with neat TPU, the average specific extinction area (AvSEA) values of all TPU composites decreased by varying degrees. Moreover, TPU3 has the lowest AvSEA value of $106.0 \mathrm{~m}^{2} / \mathrm{kg}$ in all samples, with a decrease of $33.6 \%$. Therefore, these results show that $\mathrm{La} \mathrm{LDH} / \mathrm{GO}$ has a better smoke suppression effect.

3.4. Char Residues Analysis of TPU Composites. The structure and morphology of carbon layer also affect the flame retardancy of polymers [32]. In order to further explore the flame retardancy mechanism in condensed phase, the morphology and structure of the char residues left after CCT were investigated by SEM and XRD. The SEM images of char residues of TPU and TPU composites after CCT are presented in Figure 8. As Figure 8(a) shows, when neat TPU is burned out, the char residue is loose, porous, and fragile, which shows that TPU is a porous material and prone to smoldering. As for TPU1 containing MgAl LDH shown in Figure $8(\mathrm{~b})$, the number of holes on the surface of char 


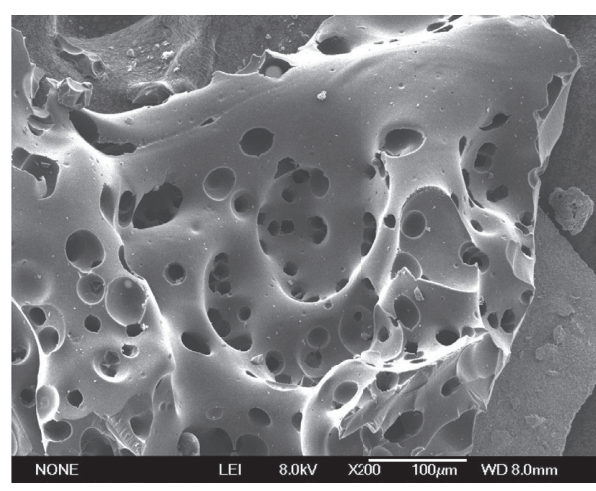

(a)

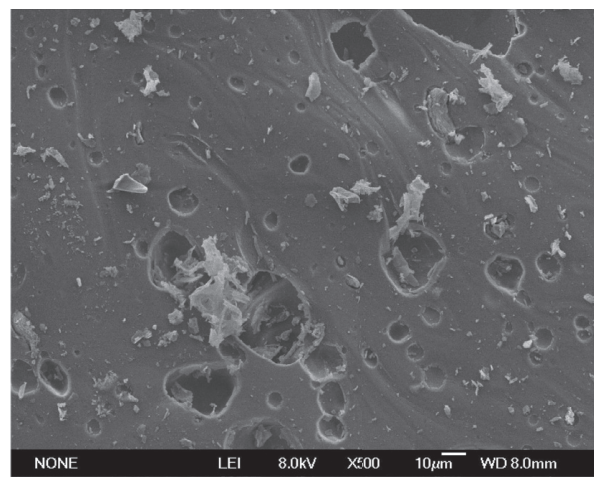

(c)

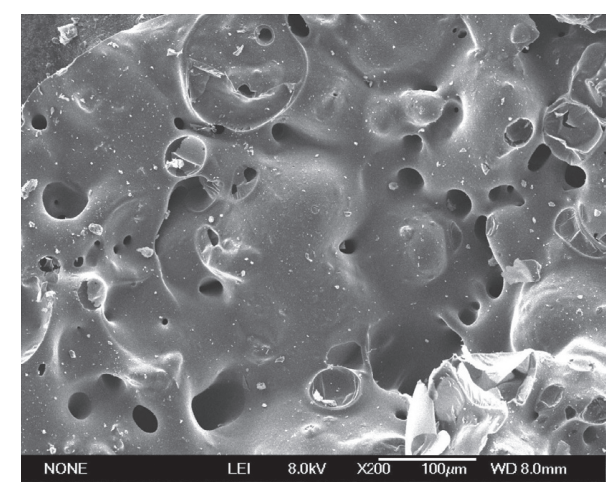

(b)

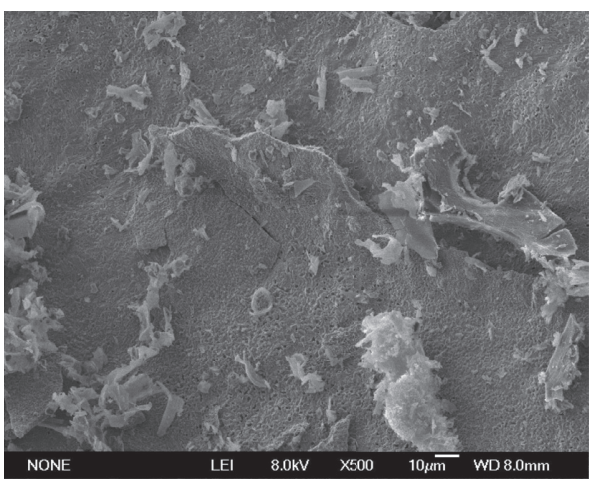

(d)

FIgURE 8: SEM images of char residues of (a) TPU, (b) TPU1, (c) TPU2, and (d) TPU3 after CCT.

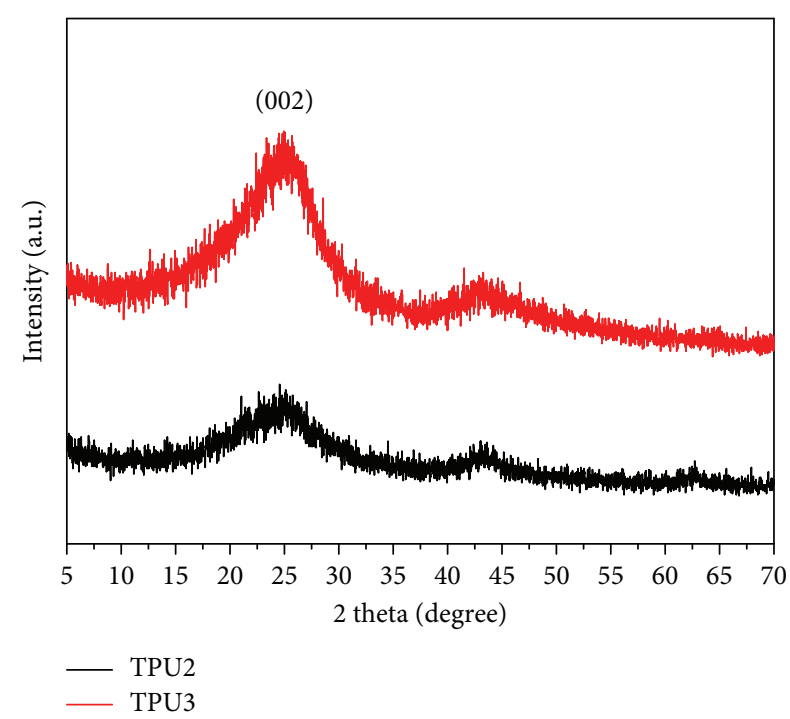

FIGURE 9: XRD patterns of char residues of TPU2 and TPU3 composites.

residue are reduced, but the char residue is still loose. Compared with neat TPU, the holes on the surface of char residue from TPU2 (with $0.05 \mathrm{La} \mathrm{LDH}$ added) become hollows and the cracks basically do not exist. The main reason for this phenomenon is that $0.05 \mathrm{La} \mathrm{LDH}$ plays a catalytic role in the pyrolysis of TPU, thus promoting the cross-linking of TPU. Noticeably, after the incorporation of
$0.05 \mathrm{La} \mathrm{LDH}$ and GO into TPU, it can be seen that the surface of char residue of TPU3 is compact and there are no holes and cracks, showing that GO can enhance the barrier effect of carbon layer. Figure 9 shows the XRD patterns of char residues of TPU 2 and TPU 3 composites. It can be seen that (002) diffraction peak representing the symmetric vibration of graphite crystallite appears near $25^{\circ}$ for both TPU2 and TPU3, which further indicates the existence of graphitized structure in the carbon layer. However, the intensity of the (002) diffraction peak of TPU3 is stronger than that of TPU2, which means that the carbon layers formed by GO and $0.05 \mathrm{La} \mathrm{LDH}$ after combustion constitute an enhanced double-carbon layer structure, thus playing a more effective barrier role [33].

\subsection{Thermal Behavior of TPU Composites.} Thermogravimetric analysis (TGA) is a thermal analysis technique for measuring the relationship between the quality and temperature change of the samples under programmed temperature control, which is used to investigate the thermal stability and composition of the materials [34]. The TGA and derivative thermogravimetry (DTG) curves of neat TPU and TPU composites in nitrogen atmosphere are shown in Figure 10, and the detailed data are summarized in Table 3. As shown in Figure 10(a) and 10(b), $T_{\text {onset }}$ (defined as the temperature at which the mass loss of sample is $5 \mathrm{wt} \%$ ) and $T_{\max }$ (defined as the maximum temperature at which the mass loss rate of sample is the fastest) decreased in different levels in 


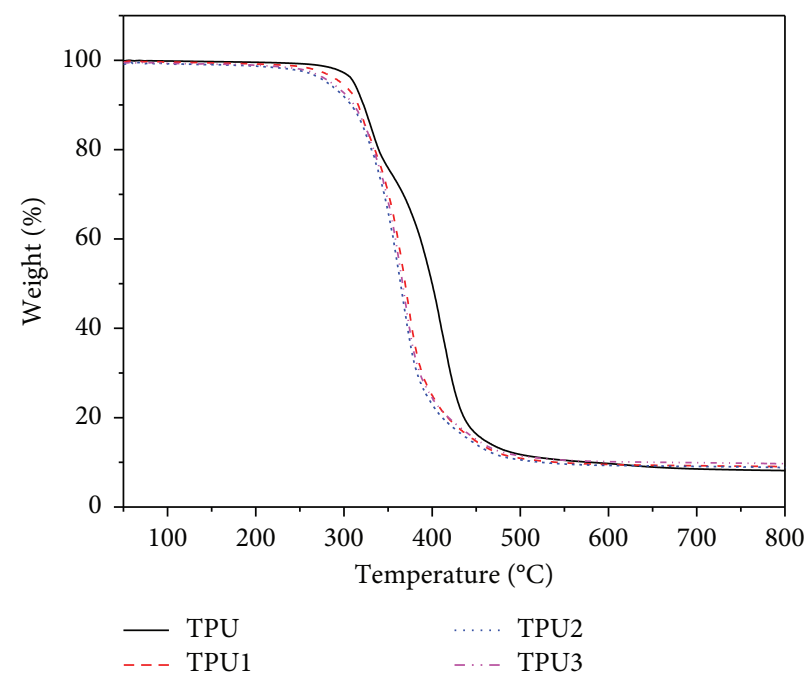

(a)

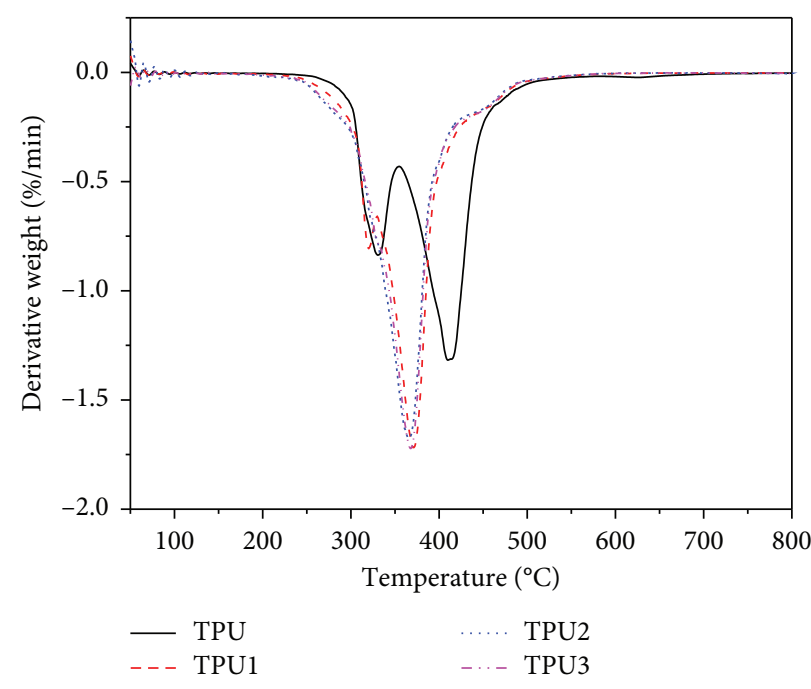

(b)

FIgURe 10: TGA (a) and DTG (b) curves of TPU and TPU composites.

TABle 3: TGA data of TPU and TPU composites in nitrogen atmosphere.

\begin{tabular}{lccc}
\hline Sample & $T_{\text {onset }}\left({ }^{\circ} \mathrm{C}\right)$ & $T_{\max }\left({ }^{\circ} \mathrm{C}\right)$ & Char yield $(\%)$ \\
\hline TPU & 311.1 & 417.6 & 8.2 \\
TPU1 & 299.2 & 374.5 & 8.4 \\
TPU2 & 284.2 & 369.6 & 8.8 \\
TPU3 & 288.5 & 372.0 & 9.7
\end{tabular}

comparison with neat TPU. In the meantime, the flame retardancy of polymers is closely related to their char yield during pyrolysis or combustion. It can be seen form Table 3 that the char residues of TPU1, TPU2, and TPU3 are $8.4 \%$, $8.8 \%$, and $9.7 \%$ at $800^{\circ} \mathrm{C}$, which are higher than those of neat TPU, especially the TPU3 with La LDH/GO is added. The thermal stability of TPU matrix improved by La LDH/GO can be attributed not only to the catalytic effect of $0.05 \mathrm{La} \mathrm{LDH}$ on the formation of protective carbon layer, but also to the high thermal conductivity and physical barrier effect of GO [35]. The heat conduction and coke blockage produce the so-called labyrinth effect, resulting in heat and combustion gas must follow the tortuous path to fuel, which effectively prevents the spread of flame [31, 36].

\section{Conclusions}

To sum up, a La LDH/GO hybrid was synthesized by the hydrothermal method and characterized using XRD, FTIR, and TEM. The results showed that $\mathrm{La}^{3+}$ has been doped into $\mathrm{MgAl} \mathrm{LDH}$, and La LDH/GO hybrid was successfully prepared. Afterwards, TPU composites containing MgAl LDH, $0.05 \mathrm{La} \mathrm{LDH}$, and $\mathrm{La} \mathrm{LDH} / \mathrm{GO}$ were prepared through melt blending, respectively. Of all TPU composites, the TPU3 filled with $2 \mathrm{wt} \% \mathrm{La} \mathrm{LDH} / \mathrm{GO}$ had better flame retardancy and smoke suppression performance. Compared with neat TPU, the PHRR and PSPR values of TPU3 decreased by
$33.1 \%$ and $51 \%$, respectively. Meanwhile, the char residue quality and char yield of TPU3 were also further improved. The reduced fire hazard of TPU3 could attribute to the interaction of $0.05 \mathrm{La} \mathrm{LDH}$ and GO. For one thing, the flame retardancy of $0.05 \mathrm{La} \mathrm{LDH}$ is due to the combination of heat absorption, gas dilution, and char formation. On the other hand, the carbon layers formed by GO and 0.05 La LDH after combustion constitute an enhanced double-carbon layer structure, thus playing a more effective barrier role.

\section{Data Availability}

All data used to support the findings of this study may be released upon application to the Qingdao University of Science and Technology, who can be contacted at qdkjdx@ qust.edu.cn.

\section{Conflicts of Interest}

The authors declare that there are no conflicts of interest regarding the publication of this paper.

\section{Acknowledgments}

The authors gratefully acknowledge the National Natural Science Foundation of China (No. 51572138), the Key R\&D Project of Shandong Province (No. 2019GSF109001, 2019CSF109080 and 2017GSF217013), the Shandong Provincial Natural Science Foundation, China (No. ZR2018BB072), the Original Innovation Project of Qingdao City (No. 19-6-2-23-cg), the Foundation of State Key Laboratory of High-Efficiency Utilization of Coal and Green Chemical Engineering (Nos. 2018-K09 and 2018-K43), Key Laboratory of Coastal Environmental Processes and Ecological Remediation, YICCAS (No. 2018KFJJ02), and 
Opening Project of Shandong Ecochemical Engineering Collaborative Innovation Center (No. XTCXQN02).

\section{References}

[1] Y. Gao, J. Wu, Q. Wang, C. A. Wilkie, and D. O’Hare, "Flame retardant polymer/layered double hydroxide nanocomposites," Journal of Materials Chemistry A, vol. 2, no. 29, pp. 10996-11016, 2014.

[2] K. Zhao, W. Xu, L. Song, B. Wang, H. Feng, and Y. Hu, "Synergistic effects between boron phosphate and microencapsulated ammonium polyphosphate in flame-retardant thermoplastic polyurethane composites," Polymers for Advanced Technologies, vol. 23, no. 5, pp. 894-900, 2012.

[3] A. Toldy, G. Harakály, B. Szolnoki, E. Zimonyi, and G. Marosi, "Flame retardancy of thermoplastics polyurethanes," Polymer Degradation and Stability, vol. 97, no. 12, pp. 2524-2530, 2012.

[4] A. B. Morgan and J. W. Gilman, "An overview of flame retardancy of polymeric materials: application, technology, and future directions," Fire and Materials, vol. 37, no. 4, pp. 259-279, 2013.

[5] X. Chen, Y. Jiang, J. Liu, C. Jiao, Y. Qian, and S. Li, "Smoke suppression properties of fumed silica on flame-retardant thermoplastic polyurethane based on ammonium polyphosphate," Journal of Thermal Analysis and Calorimetry, vol. 120, no. 3, pp. 1493-1501, 2015.

[6] G. Huang, S. Wang, P. a. Song, C. Wu, S. Chen, and X. Wang, "Combination effect of carbon nanotubes with graphene on intumescent flame-retardant polypropylene nanocomposites," Composites Part A: Applied Science and Manufacturing, vol. 59, no. 2, pp. 18-25, 2014.

[7] S. Bourbigot, T. Turf, S. Bellayer, and S. Duquesne, "Polyhedral oligomeric silsesquioxane as flame retardant for thermoplastic polyurethane," Polymer Degradation and Stability, vol. 94, no. 8, pp. 1230-1237, 2009.

[8] Q. Wang and D. O'Hare, "Recent advances in the synthesis and application of layered double hydroxide (LDH) nanosheets," Chemical Reviews, vol. 112, no. 7, pp. 4124-4155, 2012.

[9] Y. Han, Y. Wu, M. Shen et al., "Preparation and flame retardancy of polystyrene nanocomposites based on layered double hydroxides," Polymer Composites, vol. 38, no. 8, pp. 1680-1688, 2015.

[10] S. Zhang, Y. Yan, W. Wang et al., "Intercalation of phosphotungstic acid into layered double hydroxides by reconstruction method and its application in intumescent flame retardant poly (lactic acid) composites," Polymer Degradation and Stability, vol. 147, pp. 142-150, 2018.

[11] Z. B. Peng, B. Hu, Q. D. Su, and J. Z. Qu, "Study on mechanism of rear earth PVC stabilize," Journal of Rare Earths, vol. 21, no. 3, p. 328, 2003.

[12] R. Wen, Z. Yang, H. Chen, Y. Hu, and J. A. Duan, "Zn-Al-La hydrotalcite-like compounds as heating stabilizer in PVC resin," Journal of Rare Earths, vol. 30, no. 9, pp. 895-902, 2012.

[13] S. Yi, Z.-H. Yang, S.-W. Wang et al., "Effects of MgAlCe-CO3 layered double hydroxides on the thermal stability of PVC resin," Journal of Applied Polymer Science, vol. 119, no. 5, pp. 2620-2626, 2011.

[14] Z. Matusinovic and C. A. Wilkie, "Fire retardancy and morphology of layered double hydroxide nanocomposites: a review," Journal of Materials Chemistry, vol. 22, no. 36, pp. 18701-18704, 2012.
[15] B. Sang, Z.-W. Li, X.-H. Li, L.-G. Yu, and Z.-J. Zhang, "Graphene-based flame retardants: a review," Journal of Materials Science, vol. 51, no. 18, pp. 8271-8295, 2016.

[16] W. Xu, B. Zhang, B. Xu, and A. Li, "The flame retardancy and smoke suppression effect of heptaheptamolybdate modified reduced graphene oxide/layered double hydroxide hybrids on polyurethane elastomer," Composites Part A: Applied Science and Manufacturing, vol. 91, pp. 30-40, 2016.

[17] S. Park, J. B. An, R. D. Piner et al., "Aqueous suspension and characterization of chemically modified graphene sheets," Chemistry of Materials, vol. 20, no. 21, pp. 6592-6594, 2008.

[18] S. P. Lonkar, B. Kutlu, A. Leuteritz, and G. Heinrich, "Nanohybrids of phenolic antioxidant intercalated into MgAl-layered double hydroxide clay," Applied Clay Science, vol. 71, no. 1, pp. 8-14, 2013.

[19] J. Wang, Q. Pan, Q. Liu et al., "Synthesis and photoluminescence properties of europium doped $\mathrm{Mg}$-Al layered double hydroxides intercalated with anions," Solid State Sciences, vol. 14, no. 5, pp. 562-566, 2012.

[20] K. Zhou, Z. Gui, Y. Hu, S. Jiang, and G. Tang, "The influence of cobalt oxide-graphene hybrids on thermal degradation, fire hazards and mechanical properties of thermoplastic polyurethane composites," Composites Part A: Applied Science and Manufacturing, vol. 88, pp. 10-18, 2016.

[21] Y. Q. Han, T. Q. Wang, X. X. Gao, T. X. Li, and Q. Zhang, "Preparation of thermally reduced graphene oxide and the influence of its reduction temperature on the thermal, mechanical, flame retardant performances of PS nanocomposites," Composites Part A: Applied Science and Manufacturing, vol. 84, pp. 336-343, 2016.

[22] Y.-T. Pan, J. Wan, X. Zhao, C. Li, and D.-Y. Wang, "Interfacial growth of MOF-derived layered double hydroxide nanosheets on graphene slab towards fabrication of multifunctional epoxy nanocomposites," Chemical Engineering Journal, vol. 330, pp. 1222-1231, 2017.

[23] L. Zhang, X. Zhang, L. Shen et al., "Enhanced high-current capacitive behavior of graphene/CoAl-layered double hydroxide composites as electrode material for supercapacitors," Journal of Power Sources, vol. 199, pp. 395-401, 2012.

[24] B. Schartel and T. R. Hull, "Development of fire-retarded materials-interpretation of cone calorimeter data," Fire Materials, vol. 31, no. 5, pp. 327-354, 2007.

[25] Z. Matusinovic, H. Lu, and C. A. Wilkie, "The role of dispersion of LDH in fire retardancy: the effect of dispersion on fire retardant properties of polystyrene/Ca-Al layered double hydroxide nanocomposites," Polymer Degradation and Stability, vol. 97, no. 9, pp. 1563-1568, 2012.

[26] W. Xu, X. Wang, Y. Liu, W. Li, and R. Chen, "Improving fire safety of epoxy filled with graphene hybrid incorporated with zeolitic imidazolate framework/layered double hydroxide," Polymer Degradation and Stability, vol. 154, pp. 27-36, 2018.

[27] J. R. Potts, D. R. Dreyer, C. W. Bielawski, and R. S. Ruoff, "Graphene-based polymer nanocomposites," Polymer, vol. 52, no. 1, pp. 5-25, 2011.

[28] A. Edenharter, P. Feicht, B. Diar-Bakerly, G. Beyer, and J. Breu, "Superior flame retardant by combining high aspect ratio layered double hydroxide and graphene oxide," Polymer, vol. 91, no. 17, pp. 41-49, 2016.

[29] L. Liu, X. L. Zhao, C. Y. Ma, X. L. Chen, S. X. Li, and C. M. Jiao, "Smoke suppression properties of carbon black on flame retardant thermoplastic polyurethane based on ammonium polyphosphate," Journal of Thermal Analysis and Calorimetry, vol. 126, no. 3, pp. 1821-1830, 2016. 
[30] S. Xu, L. Zhang, Y. Lin, R. Li, and F. Zhang, "Layered double hydroxides used as flame retardant for engineering plastic acrylonitrile-butadiene-styrene (ABS)," Journal of Physics and Chemistry of Solids, vol. 73, no. 12, pp. 1514-1517, 2012.

[31] S. Wang, R. Gao, and K. Zhou, "The influence of cerium dioxide functionalized reduced graphene oxide on reducing fire hazards of thermoplastic polyurethane nanocomposites," Journal of Colloid and Interface Science, vol. 536, pp. 127-134, 2019.

[32] J. Yu, Q. Wang, D. O'Hare, and L. Sun, “Preparation of two dimensional layered double hydroxide nanosheets and their applications," Chemical Society Reviews, vol. 46, no. 19, pp. 5950-5974, 2017.

[33] S. Liu, H. Yan, Z. Fang, Z. Guo, and H. Wang, "Effect of graphene nanosheets and layered double hydroxides on the flame retardancy and thermal degradation of epoxy resin," RSC Advances, vol. 4, no. 36, pp. 18652-18659, 2014.

[34] X. Chen, C. Jiao, and J. Zhang, "Thermal and combustion behavior of ethylene-vinyl acetate/aluminum trihydroxide/ Fe-montmorillonite composites," Polymer Engineering \& Science, vol. 52, no. 2, pp. 414-419, 2012.

[35] C. Lee, X. Wei, J. W. Kysar, and J. Hone, "Measurement of the elastic properties and intrinsic strength of monolayer graphene," Science, vol. 321, no. 5887, pp. 385-388, 2008.

[36] D. Wang, Q. Zhang, K. Zhou, W. Yang, Y. Hu, and X. Gong, "The influence of manganese-cobalt oxide/graphene on reducing fire hazards of poly(butylene terephthalate)," Journal of Hazardous Materials, vol. 278, pp. 391-400, 2014. 